seen during the same time period: (a) 180 persons presenting for reasons other than dog bites (b) 121 persons presenting with nondog bite injuries and (c) 126 persons presenting with non-injury conditions. Persons with conditions having known associations with gender were excluded from each control series.

Results ORs comparing males to females were (a) OR 0.8, 95\% CI 0.5 to 1.3 , (b) OR $0.6,95 \%$ CI 0.4 to 1.0 and (c) OR 1.2, 95\% CI 0.7 to 1.9$)$.

Conclusion Our results do not support a hypothesis of a higher dog bite risk for males. We discuss them in the context of the type of injury under consideration, the different research questions implicit in each choice of control group and potential bias, especially as it relates to hospital-based case-control studies.

\section{SP6-57 INFLUENCE OF MATERNAL PERCEPTION ABOUT THE QUALITY OF ANTENATAL COUNSELLING ON THE CHOICE OF DELIVERY ATTENDANT AT WEST BANDUNG DISTRICT, 2010}

doi:10.1136/jech.2011.142976q.28

D Oktavia. ${ }^{*}$ Field Epidemiology Training Program, Jakarta, Indonesia

Introduction This study investigated the influence of maternal perceptions about the quality of antenatal counselling on the choice of birth attendant.

Methods A case control study was conducted between June and August 2010 in West Bandung district, Indonesia. Cases are mothers who had antenatal visits to midwife but choose paraji-a traditional birth attendant - at delivery between February and July 2010 and lived in the study area. Controls are mothers who had antenatal visits to midwife and choose midwife at delivery between February and July 2010 and lived in the study area.

Results Samples were consisted of 122 cases and 156 controls. Multivariate analyses showed that mothers who had poor perception of antenatal counselling were 1.88 times more likely to choose Paraji as birth attendant (95\% CI 1.10 to 3.23). This was after controlling for other variables including maternal age, maternal education, number of deliveries, number of antenatal, decision maker and health insurance. Mothers who visited midwives who often used foreign or medical terminology during counselling were 1.7 times (95\% CI 1.01 to 3) more likely to use Paraji as birth attendant. Not using visual aids also led to a preference for Paraji birth attendants (OR 2.4, 95\% CI 1.31 to 4.51).

Conclusions The study suggested that poor perception about antenatal counselling steered mothers to using traditional birth attendant rather than midwives and other types of birthing care. Recommendations included providing midwives' skills in interpersonal communication and counselling, and to provide multiple choices of visual aids to support the counselling process.

\section{SP6-58 DETERMINANTS OF VILLAGE HEALTH VOLUNTEER'S BEHAVIOUR ON RECORDING AND REPORTING DIARRHOEA CASES IN TEMANGGUNG DISTRICT, 2010}

doi:10.1136/jech.2011.142976q.29

\section{Ramadhoni.* Field Epidemiology Training Program, Bekasi, Indonesia}

Introduction Diarrhoea is the second biggest disease in top ten diseases in primary healthcare in Temanggung. Monitoring diarrhoea is one of Village Health Volunteer's Integrated Service Pos duty. This research aimed to achieve determinants (age, education, occupation, duration of occupation, marriage's status, knowledge, attitude, facilities, training, outbreak, information) of Village Health Volunteer's behaviour for recording and reporting diarrhoea's cases.
Methods Design of this research is cross sectional. Population is Village Health Volunteer in Temanggung District. Sample size is 208 Village Health Volunteers. The data were collected by interviewing respondents with using questionnaire.

Results Most of Village Health Volunteers have bad behaviour in recording \& reporting diarrhoea's cases $(57.69 \%)$. The study results show that factors associated with village health volunteers are education background (OR 2.189, 95\% CI 1.177 to 4.073), occupation (OR 2.474, 95\% CI 1.356 to 4.514), training (OR 0.119, 95\% CI 0.024 to 0.585 ), and knowledge (OR 1.895 , 95\% CI 1.043 to 3.442 ). Conclusions Determinants of village health behaviour in recording and reporting diarrhoea cases are education, occupation, knowledge, and training. District Health office is recommended to hold a training with respect to education background. Education and occupation should be considered in village health volunteer's recruitment.

\section{SP6-59 FACTORS ASSOCIATED WITH DIARRHOEAL ILLNESS IN LEBAKWANGI HEALTH CENTER WORKING AREA, CIGUDEG SUB DISTRICT, BOGOR DISTRICT, INDONESIA IN 2009}

doi:10.1136/jech.2011.142976q.30

Listiono -,* N Prihartono, E Wulantari. Public Health Faculty of Indonesia University, Jakarta, Indonesia

Introduction In Bogor District, Indonesia diarrhoea is still a very serious public health problem frequently occurring in outbreaks. In 2009 there were eight outbreaks of diarrhoea, one in the working area of Lebakwangi Public Health Center, Cigudeg Sub District, affecting 258 patients with a case-fatality rate of $0.78 \%$. The aim of this study was to examine the factors associated with diarrhoea in the working area of Lebakwangi Public Health Center.

Methods A case-control study was carried out. This study examined 130 cases who were patients with diarrhoea in Lebabkwangi Public Health Center territory in August 2009 and 130 controls who were persons without diarrhoea from the same population. Data were collected by direct interviews using a structured questionnaire which included questions on sociodemographic, behavioural and environmental variables. Data were analysed using Stata.

Results In multi-variate analyses three factors were associated with experiencing diarrhoea: washing eating equipment without soap (OR 3.41 (95\% CI 2.00 to 5.80)), family latrine availability (OR 2.66 (1.43 to 4.95$)$ ) and lack of availability of clean water sources (OR 1.83 (1.03 to 3.26$)$ ).

Conclusions Diarrhoeal illness was associated with washing eating equipment without soap, availability of family latrine and lack of availability of clean water source, with the strongest association between diarrhoeal illness and washing eating equipment with soap.

\section{SP6-60 HAND WASHING PRACTICE AMONG HEALTHCARE PROVIDERS IN A TERTIARY HOSPITAL IN SOUTH EAST NIGERIA}

doi:10.1136/jech.2011.142976q.31

${ }^{1} \mathrm{U}$ Onyeonoro, ${ }^{*}{ }^{2} \mathrm{~A}$ Ukegbu, ${ }^{3} 0$ Emelumadu, ${ }^{4} 0$ Kanu. ${ }^{1}$ Abia State University, Aba, Abia State, Nigeria; ${ }^{2}$ Federal Medical Center, Umuahia, Abia State, Nigeria; ${ }^{3}$ Nnamdi Azikiwe University, Nnewi, Anambra State, Nigeria; ${ }^{4}$ Lagos University Teaching Hospital, Idi-Araba, Lagos, Nigeria

Introduction Hand washing been demonstrated to significantly reduce transmission of hospital-acquired infection. This study was carried to ascertain hand washing practice among care providers in a tertiary facility in Nigeria. 